\title{
Research on the Development of Information Intensive Green Logistics
}

\author{
Jintian $\mathrm{GE}^{1, \mathrm{a}}$, Daiwei GUO ${ }^{2, \mathrm{~b}}$, Qiang $\mathrm{LI}^{3, \mathrm{c}}$ \\ ${ }^{1}$ Business School, University of Jinan, Shandong, China, 250002 \\ 2 Business School, University of Jinan, Shandong, China, 250002 \\ ${ }^{3}$ Business School, University of Jinan, Shandong, China, 250002 \\ âSe_gejt@ujn.edu.cn, bdaiwei19930@163.com, ${ }^{c}$ liyuxian_1992@163.com
}

Keyword: Logistics information platform; Green logistics; Logistics intelligent

Abstract. Empty and round trip problem has become an important bottleneck restricting logistics enterprises to reduce costs and efficiency. Build advanced logistics information system and comprehensive information service platform to achieve intelligent logistics, Development of information intensive green logistics is an important choice.

\section{Introduction}

The State Council issued the "Long-term development of the logistics industry planning (2014-2020)".

The planning points out that we need to strengthen Compass navigation system, Internet of things, cloud computing, data, mobile Internet and other advanced information technology in the logistics field applications. The purpose of green logistics is to reduce the enterprise's environmental pollution, reduce resource consumption, and enhance corporate social responsibility while improving its market competitiveness.

To solve the problem of empty truck transportation problem, it is not only the requirement of cost reduction, but also the important content of developing green logistics. To this end, we need to introduce advanced information systems and the construction of integrated logistics platform, and to optimize the transportation path and vehicle stowage to realize the sharing and effective integration of information resources among different logistics nodes. Therefore, the development of information intensive green logistics, logistics industry for the transformation and upgrading, connotation development of great significance.

\section{The difficulties faced by developing information intensive green logistics}

Ali Group jointed Yuantong, Yunda and other courier companies set up a "rookie Union", designed to solve the days of TMALL, Taobao and other business platform to sell goods can be fast and efficient transport and distribution, and cooperation between partners to achieve win-win situation, to achieve cost reduction efficiency.

At present, China's major logistics park settled in the scattered fleet, small and medium enterprises are more independent of the state of operation, the respective information systems are also independent operations, the formation of an "information island." To solve the empty round trip only to stay in the clerk to run the business stage, causing the phenomenon of the main reasons are: 
Green logistics and the concept of shared resources has not yet universal. All sectors of society are recognized modern logistics in the national economy in the development of basic industrial status, however businesses and consumers for the development of green logistics is very shallow, they thought mainly lies in the development of green logistics infrastructure investment, including the introduction of gas vehicles, reduce the use high contamination of raw materials, waste recycling, and ignore the software into the important role in the development of green logistics. Some companies believe that development of green logistics is the responsibility of the government, has nothing to do with the enterprise itself. In addition, the competitive relationship between logistics enterprises, the sources of information such as resources, corporate secrets than on the tooling more reluctant to information resources sharing.

Lack of guidance and confidence. China's logistics industry as a whole in the scale of expansion, rapid development stage, small and medium enterprises is the main body. In many logistics enterprises, more than half of the small size, low anti-risk ability, a single mode of operation of small cargo transport, agents and other enterprises. These small cargo transport enterprises start low threshold, the development of arbitrary strong, mainly for the supply and market, with the development of enterprises to establish a set of their own management system. But with the increasing pressure from industry competition, many business leaders are aware of the need to solve the problem of empty travel due to tight supply, need to find the same needs through effective channels partners, through the use of intelligent logistics technology to achieve good cooperation Reached. There is the idea of achieving business complementarity, but because of the lack of professional guidance, it is difficult to achieve real-time information sharing, the rational distribution of benefits, resulting in the short term to end cooperation.

Poor compatibility of logistics facilities and equipment. The premise of cooperation is that the dual (multi) party components can be compatible, including hardware compatibility and software compatibility. Hardware compatibility problems obviously, due to the early operation of various enterprises, logistics vehicles and other hardware equipment are introduced in accordance with the characteristics of their goods, prone to both sides of the cargo transport equipment difficult to match the problem. When there is sufficient supply side, the vehicle turnover is not long, while the other side of the lack of supply, but because the vehicle is not appropriate, it is difficult to achieve vehicle resource sharing.

Information platform compatibility is poor. With the logistics industry to eliminate its own vehicle trends, most of the logistics company to introduce their own information management system to manage vehicles and employees. In order to realize the integration and sharing of resources and realize the real-time sharing of the source and source data, it is necessary to realize the seamless docking between different information platforms, analyze the supply information through the system data, complete the matching of the goods and vehicles, On the distribution of benefits, in a reasonable arrangement of transport vehicles to reduce the rate of idle at the same time, to reduce the uneven distribution of benefits occurred. However, due to the different development of information systems companies, there are different programming framework, it is difficult to achieve system compatibility, which is hindering the nodes of enterprises to achieve cooperation in the main bottleneck problem. It is difficult to meet the growing demand for logistics 
and transportation, but also with the use of high-tech development of resource intensive green logistics contrary to the purpose.

Lack of scientific system of interest distribution and risk management. Less-than-one carload transport logistics business has two major characteristics of uncertainty and risk. The uncertainty is cargo type and destination of uncertainty, it also increased the difficulty of the vehicle matching. Multi-party cooperation ultimate aim is to make lowest cost and benefit maximization. But because of the goods in the presence of uncertainty, such as volume, weight, area, and currently in use by a pure, weight and other valuation method is easy to cause uneven distribution of interests problem; Another risk is greater than the carrier vehicle receiving enterprise, the opportunity cost is hard to calculate, risk-sharing system is not perfect, makes the reliable degree of cooperation between enterprise and the big discounts.

\section{Measures to Accelerate the Development of Information Intensive Green Logistics}

The whole implementation process is a systematic project, needs the government, enterprises and consumers engaged in a concerted effort to complete.

Government to promote the development of green logistics. Want green logistics in our country have a greater influence, first of all need the government in the laws and regulations and policies to be improved, the green logistics positioning in the sustainable development of an important part of the strategy. The second is to increase the green logistics propaganda, so that the community set a green logistics, green management concept, cultivate green logistics thinking; let logistics enterprises understand that environmental pollution is not only to strictly control the car displacement, but also between logistics enterprises " Inward aggregation ", through the information system to achieve business complement this media, to focus on the advantages of the logistics industry. Third, we must regularly carry out relevant seminars, training courses, improve the ability of logistics business managers. Fourth, the development of relevant support policies, to give active application platform connected to achieve the common distribution of corporate funds.

Promote the standardization of logistics construction. Logistics standardization not only refers to the standardization of facilities and equipment, but also should focus on the standardization of software investment. Logistics industry in the information system construction process need to establish a complete industry standards, also in accordance with the specified standard programming architecture, computer language and other professional and technical support. After the completion of the system need to leave a data external interface, allowing access to other systems and data exchange.

Pay attention to professional personnel training and encourage team innovation. Logistics industry transformation and upgrading, the lack of professional and comprehensive personnel. To guide the logistics enterprises to achieve the transformation and upgrading of information technology, intelligent logistics facilities and equipment intelligent use, you need to cultivate a comprehensive logistics personnel, requiring both the logistics operation process, but also understand the development of logistics information systems. In the realization of the logistics platform docking process, professionals can broaden the needs of enterprises into professional logistics terminology, and technical personnel to communicate into a viable logistics information system development language.

Building intelligent logistics information system to ensure optimal distribution of benefits. In the information system construction process, in addition to leaving the interface to allow other systems to access, but also need to make it more intelligent algorithm. The huge amount of logistics business data in the multi-system exchange at the same time, it can be based on the volume of goods, weight, area, transport mileage and other factors affecting the cost of transport, intelligent 
operation and transportation costs, to complete the optimal distribution of benefits. Through the intelligent dynamic optimization of the transport path, the real-time sharing of the business data involved in the transportation process makes the consumers, the receiving party and the carrier both pay attention to the dynamic and risk of the goods in real time.

\section{Conclusions}

The development of green logistics needs to solve the problem of logistics information system based on the innovation of management mode. We should innovate the technology, equipment, management model, etc. by using the modern information technology such as the Internet of things, big data, cloud computing and communication technology, we can realize the integrated logistics management. The whole implementation process is a systematic project, which requires the government, enterprises and even consumers to work together to complete.

\section{Major Authors}

${ }^{1}$ Jintian GE, male, professor of business school of University of Jinan ,doctor, master guide, Email: Se_gejt@ujn.edu.cn

${ }^{2}$ Daiwei GUO, male, Business School of University of Jinan Logistics Engineering graduate, Email: 296021247@qq.com

${ }^{3}$ Qiang LI, male, Business School of University of Jinan logistics engineering graduate, Email: liyuxian_1992@163.com

\section{References}

[1]Rongli SHI. Construction of Information Platform for Intelligent Logistics Park Based on Big Data [J]. Enterprise Economy, 2016.03:134-138 ( in Chinese )

[2]Yusheng TU. Discussion on Modern Green Logistics Management and Countermeasures [J]. Shanxi Agriculture,2016.14:125 ( in Chinese )

[3]Renshu LUO. Construction of Intelligent Logistics Information Platform [J]. Logistics Engineering and Management.2014.01:80-81 ( in Chinese ) 